\title{
El discurso épico sobre el COVID-19 en la cobertura mediática de la televisión chilena
}

The Epic Discourse about COVID-19 over the Mediatic

Coverage in Chilean Television

Recepción: 30/11/2020, revisión: 04/03/2021, aceptación: 30/03/2021, publicación: septiembre de 2021

https://revistas.uasb.edu.ec/index.php/uru

(D) Eduardo Román Álvarez

eduardo.roman@usach.cl

Universidad de Santiago de Chile (Santiago, Chile)

https://orcid.org/0000-0003-4224-0128

(D) Pía Fernanda Ibarra Yáñez

pia.ibarra.y@usach.cl

Universidad de Santiago de Chile (Santiago, Chile)

https://orcid.org/0000-0003-0973-410X

(D) Camila Scarlett Amoyao Bravo

camila.amoyao@usach.cl

Universidad de Santiago de Chile (Santiago, Chile)

https://orcid.org/0000-0001-9106-7451
(D) Romina Belén Orellana Villagra

romina.orellana.v@usach.cl

Universidad de Santiago de Chile (Santiago, Chile)

https://orcid.org/0000-0002-1012-0167

(D) Constanza Sofía Valle Parra

constanza.valle@usach.cl

Universidad de Santiago de Chile (Santiago, Chile)

https://orcid.org/0000-0002-8584-6317

(ID) Victoria Alejandra Lizárraga Ojeda

victoria.lizarraga@usach.cl

Universidad de Santiago de Chile (Santiago, Chile)

https://orcid.org/0000-0001-6861-5114

DOI https://doi.org/10.32719/26312514.2021.4.4

\section{Resumen}

El discurso político suele adquirir un formato épico, particularmente cuando las crisis sociales toman dimensiones mayores. En Chile, las dificultades de gobernabilidad producidas en el estallido social de 2019 se sumaron a la intempestiva llegada de un nuevo virus, el COVID-19, lo que generó un nuevo cuadro de incertidumbres y reformulaciones políticas que la prensa recogió en el mismo carácter narrativo con que la política chilena se ha presentado históricamente. Héroes mesiánicos, enemigos poderosos, traiciones y otros elementos dramáticos circularon frecuente y dominantemente en el medio periodístico más influyente: la televisión. Este estudio, que analizó las noticias de los cuatro canales de señal abierta más importantes de Chile (Mega, Chilevisión, TVN y Canal 13), remite al discurso épico que presentó la pantalla chica como referencia de los acontecimientos producidos tanto en la arena política como en otros ámbitos relevantes de la vida pública, mostrando uniformidad no solo en la selección de noticias sino también en la estructura narrativa de los hechos durante la pandemia.

\section{Abstract}

Political speech tends to acquire an epic format. Particularly, when social crises have shown huge dimensions. In Chile, the governance difficulties produced by the social unrest of 2019 were added to the untimely arrival of a new virus: COVID-19, generating a 
new picture of uncertainties and political reformulations. In this way, the press adopted the same narrative character in which Chilean politics has been historically-presented. Messianic heroes, powerful enemies, betrayals, and other dramatic elements circulate frequently and dominantly in the influential journalistic medium: television. This study, which analyzed news of the four most relevant open signal channels in Chile (Mega, Chilevision, TVN y Canal 13), in the epic discourse that the small screen presented as a reference to the events that occurred in the political arena and other relevant spheres of public life. This panorama has shown uniformity not only in the selection of news but also the narrative structure of this events during the pandemic.

Palabras clave $\cdot$ Keywords

Discurso, épica, Chile, televisión.

Speech, epical, Chile, television.

Debido al alza de precios del Metro de Santiago, estudiantes de secundaria evadieron el pago del pasaje e iniciaron una protesta generalizada que culminó con el cierre de estaciones de forma indefinida el 18 de octubre de 2019. La escalada en los disturbios y manifestaciones, nunca vista desde el retorno a la democracia hace treinta años, dejó en evidencia la fragilidad del ordenamiento económico neoliberal del país (Barría 2019).

A raíz de las protestas, el presidente de Chile, Sebastián Piñera, decretó estado de emergencia y días después declaró: "Estamos en guerra contra un enemigo poderoso, implacable, que no respeta a nada ni a nadie" (Roa 2019, párr. 3). Aquella frase fue la primera de muchas que replicaría en torno a la idea de un "enemigo", en un discurso que situaba a la crisis como un campo de guerra, en la cual la parte heroica correspondía al Gobierno y sus instituciones, mientras que instalaba a sus detractores como personajes antagónicos, como villanos.

Pero los problemas no se resolvieron en el discurso. Al cumplir dos años en el poder, con un programa que fue mutando a regañadientes por la coyuntura política y social, Sebastián Piñera y su Gobierno volvieron a enfrentar un problema que amenazó seriamente la estabilidad de su mandato. Esta vez no fueron manifestantes gritando consignas al unísono en las calles los que hicieron tambalear a la Administración, sino un virus imposible de controlar a punta de bombas lacrimógenas y carros lanzaagua: el COVID-19.

Después de la crisis social de fines de 2019 y con el coronavirus marcando la pauta local, el mandatario chileno volvió al ruedo utilizando expresiones conocidas, pero ahora adaptadas a la coyuntura: "Sabemos que el coronavirus es un enemigo poderoso, cruel, implacable y que no respeta a nadie" (Neira 2020, párr. 5). De esta forma, el COVID-19 se transformó abiertamente en un personaje con un misticismo capaz de provocar desviación presupuestaria y al que se pidió, de forma diplomática, que se fuera del país, a la vez que se alentaba al enfrentamiento (Mur 2020). Es decir, los leucocitos defensores de 
la nación se levantaban en una cruzada a muerte contra los microbios enemigos, transformando la crisis sanitaria en una metáfora bélica (García 1996, 16). No es broma ni una ironía. Fue un discurso público, transmitido por todos los canales abiertos de la televisión chilena, en el cual el presidente Piñera interpeló al virus y le pidió literalmente que dejara en paz a los ciudadanos de este país.

También el ministro de Salud, Jaime Mañalich, declaró un conflicto contra el coronavirus, cuyo enfrentamiento más importante se libró en la capital del país: "Si no ejercemos con fuerza la 'Batalla de Santiago', esta guerra la vamos a perder [...]. Estaremos pendientes por ganarla”. El discurso del entonces ministro Mañalich refleja la reiteración de palabras que ha usado el presidente Sebastián Piñera para hacer referencia a tópicos como la delincuencia, la pobreza y la violencia. De esta forma se emplaza continuamente a las personas a tomar los resguardos pertinentes para protegerse del contagio y armarse contra aquel indeseado "enemigo" (Neira 2020, 00:01).

Tiempo después de la implementación de restricciones sanitarias, sin que disminuyeran las tasas de contagio, el Gobierno comenzó a emitir declaraciones que apresuraban la "vuelta a la normalidad". Siguiendo a Fuentes-García (2020), la apología belicista en la guerra contra el coronavirus encubre con su manto patriotero a un verdadero enemigo muy poderoso, el poder político, que se halla subordinado a una élite concentradora de capital que vela por sus privilegios y a la que no le importa la vida de los demás.

En la trama del coronavirus se enarbolan héroes y villanos, los buenos (nosotros) y los malos (los otros), creando un estereotipo de lo que es propio versus lo ajeno. Así se transmiten, a través de los medios de comunicación, representaciones de superioridad que suelen generalizar y simplificar al "oponente" (Páez y Pérez 2020, 605). Las metáforas de guerra son elementos habituales en la vida política y social de muchas naciones, puesto que resultan convenientes para difundir información difícil de comprender, al transformar lo complejo en algo sencillo mediante recursos simples y entendibles para la población. No obstante, estos usos lingüísticos en escenarios de crisis acaban afectando a las personas, porque impactan su sensibilidad, a la vez que moldean su conducta (Rojas et al. 2020, 709).

En el contexto político descrito en los párrafos anteriores, los noticieros de la televisión chilena reaccionaron con un esquema recurrente para informar sobre las crisis, construyendo relatos estructurados como discursos épicos, muy comunes en los debates políticos televisados. Sin embargo, esta vez la adecuación era compleja, pues el "enemigo" era la misma pandemia o su generador, el COVID-19. Precisamente para analizar esta adecuación en las narrativas periodísticas, esta investigación se ha propuesto consignar un registro histórico y analítico de cómo los medios de comunicación tradicionales han construido las noticias en un entorno de pandemia, bajo qué narrativas y cuáles son los actores involucrados. Los canales abordados para estos efectos son los principales de la televisión abierta en Chile: Mega, Chilevisión, TVN y Canal 13. El marco temporal comprende desde mayo hasta agosto de 2020. 


\section{La épica en la narración mediática}

Insertos en una épica bélica a niveles sociales y políticos, los medios de comunicación generaron un relato que posiciona como "víctimas" a quienes se han contagiado, en tanto que quienes sobrevivieron serían triunfadores y quienes fallecieron, los "perdedores de la batalla" (Rojas et al. 2020, 709).

Las víctimas poseen un doble estatus; pueden generar preocupación y conmiseración por su condición de salud, pero pueden también devenir en villanos (reforzado por las expresiones de personas sospechosas), en tanto el contagio podría ser consecuencia de no adherir a las recomendaciones sanitarias. La narrativa del villano suele considerar como peligrosos generalmente a minorías y migrantes, donde el prejuicio por sus hábitos de vida genera una condición propicia para sostener comportamientos xenófobos previos. (710; con énfasis en el original)

De acuerdo a estos autores, los villanos en esta crisis serían los periodistas y medios de comunicación, puesto que son apuntados como responsables al aprovecharse del miedo de la población y estar al servicio de los sectores dominantes. Asimismo, la industria farmacéutica también aparecería en esta categoría por obtener réditos económicos a partir del alza de precios durante la pandemia. En el mismo sentido, las "masas insensatas" igualmente se convirtieron en una "ontologización de los villanos", pues se reprueba su comportamiento y se las tacha de "egoístas e irracionales" cuando ocurren acaparamientos o disturbios (Páez y Pérez 2020, 604).

Los héroes, en cambio, fueron personificados por los expertos científicos que están en busca de una vacuna y los trabajadores de la salud (603), a quienes se demanda socialmente realizar un sacrificio y estar dispuestos a poner en riesgo su vida y la de sus familiares, trabajar en condiciones de precariedad y poner al límite sus competencias.

\section{Mediatización del discurso político}

Observar la política contingente desde las épicas discursivas, y particularmente desde los formatos narrativos de la televisión, implica varias consideraciones sobre los niveles de determinación que existen en un discurso político en la función de los medios de comunicación. En tal sentido, Silvia Gutiérrez sostiene que casi todos los discursos políticos son "filtrados" por los medios y, por lo tanto, están sujetos también a su lógica comunicacional $(2005,46)$. Por cierto, esta observación abre las interrogantes sobre los formatos que sostienen estas lógicas y cuán relevantes son las estructuras míticas. De hecho, es extraño encontrar discursos políticos ajenos al establecimiento de una misión, un protagonista llamado a realizarla y unos villanos opuestos a su consecución.

Según Valles, la comunicación política consiste en el intercambio de mensajes complementado por la toma de decisiones sobre conflictos de interés en las fases de decisiones 
políticas, como "la expresión de demandas, definición de la cuestión que es objeto de conflicto, la elaboración y negociación de propuestas de intervención, la movilización de apoyos para cada una de dichas propuestas, y la adopción y aplicación de una de ellas" (Reyes et al. 2011, 94). Y los noticiarios de televisión no tuvieron que modificar sus estructuras para narrar los sucesos que profundamente alteraban el país desde el estallido social: sencillamente se adaptaron con los personajes y formatos que venía utilizando desde hace tiempo, pese a que el rol de la prensa en las crisis de octubre de 2019 fue duramente evaluado por la ciudadanía.

Por su carácter mítico, parece lógico que sean los héroes los llamados a superar los conflictos. Enfrentado a problemas económicos estructurales y a una ciudadanía irascible, el discurso (y, por tanto, las acciones derivadas) del Gobierno chileno fue confirmando un relato que los medios de comunicación soportaban casi naturalmente.

En el mito, la misión del héroe es el bienestar de la sociedad y el sujeto elegido funciona cuando logra "salvar", ya que su rol es eminentemente mesiánico. El héroe supera las pruebas necesarias para lograr su meta, para lo cual cuenta con ayudantes, y también aparecen elementos esenciales del relato que funcionan en sentido opuesto, como apoyo a un antagonista que opera contra la misión (Barthes 1994, 239).

Las estrategias discursivas - los relatos míticos sobre la realidad- que se instalaron en las narrativas de la televisión no tuvieron, sin embargo, los resultados que la estrategia debía producir. En efecto, la enorme crisis que se desató en Chile a fines del año 2019 pareció morigerar con la irrupción del COVID-19, pero a los pocos meses los conflictos políticos y sociales se repusieron en la misma medida en que los ciudadanos se adaptaban a cuarentenas y otras restricciones que significaban la "nueva realidad".

Es importante aclarar que, en términos narrativos, derivado probablemente de la literatura, de la radio y del cine, la televisión no diferencia las estructuras diegéticas de sus formatos. Tanto las teleseries como los matinales y los programas de concursos comparten su esqueleto discursivo con las supuestas referencias a lo no ficcional del ámbito periodístico, expresado en noticiarios, reportajes y foros. De este modo, el conflicto es el choque dramático entre fuerzas o voluntades opuestas que comparten un mismo fin. Es la base de todo drama y, por lo tanto, de los argumentos, que se desarrollan cuando un sujeto comprometido con una misión choca con la fuerza oponente. Por eso, en toda la política nacional -y quizá también internacional- es difícil encontrar signos estructurales de ciudadanos, movimientos u organizaciones que sigan otra dirección discursiva, y parece natural que el presidente Piñera y sus ministros asumieran una épica que les permitiera sobrellevar conflictos sociales y políticos, sobre todo cuando los oponentes operaban bajo la misma práctica narrativa.

Antonio Sánchez-Escalonilla $(2003,106)$ describe las tramas que sostienen a los discursos políticos en la televisión. En ellas, regularmente, el conflicto social pone en tensión a uno o más personajes (el protagonista y sus amigos) y a un grupo social que asume 
el papel de antagonista. Solo que, en este caso, el rol de villano lo asumió ni más ni menos que el propio COVID-19.

\section{Metodología y materiales}

En esta investigación se analizaron diariamente las noticias emitidas por los cuatro principales canales de televisión abierta de Chile, en términos del desempeño épico de los actantes y de su carácter misional, asumiendo el conflicto dramático de los relatos periodísticos. El propósito, en este caso, fue establecer en qué grado, y con qué intensidad o frecuencia, se presenta un cierto rasgo o una variable del objeto de estudio. Para ello, el análisis se realiza desde un esquema que descompone una estructura épica, en la cual se sitúan los datos y cuya recurrencia se establece.

Si bien las técnicas cuantitativas son más descriptivas que explicativas, se utilizaron en este caso porque permiten explorar los textos en términos de sus reiteraciones estructurales, presentando sus características y elementos constitutivos. Los estudios descriptivos se caracterizan por un mínimo de interpretación y conceptualización:

Con frecuencia, la meta del investigador consiste en describir fenómenos, situaciones, contextos y sucesos; esto es, detallar cómo son y se manifiestan. Con los estudios descriptivos se busca especificar las propiedades, las características y los perfiles de personas, grupos, comunidades, procesos, objetos o cualquier otro fenómeno que se someta a un análisis. (Hernández Sampieri et al. 2014, 92)

Por estos motivos, para obtener y procesar la información en este trabajo, se estimó que el instrumento más adecuado era el análisis de contenido, un tipo de medición aplicado a un mensaje en el marco de propósitos del ámbito de las ciencias sociales o, más precisamente, una reducción sistemática del flujo del texto a un cuerpo estándar de símbolos manipulable estadísticamente, tal que represente la presencia, la intensidad o la frecuencia de ciertas características relevantes.

La medición, que se estima un componente importante, si no indispensable, implica la existencia de procedimientos de clasificación ya sea nominales, ordinales o escalares, pero "la simple producción de cifras a partir de un texto (mensaje) no justifica en sí mismo el análisis de contenido. Es su inserción en un conjunto, en una investigación tendiente a demostrar una hipótesis no obvia, lo que lo justifica" (Tinto 2013, 141-2). En sentido estricto, por lo tanto, está destinado a facilitar la descripción sistemática de los componentes semánticos y formales de todo tipo de mensaje, y la formulación de inferencias válidas acerca de los datos.

En este caso, la investigación abordó los cuatro principales canales de televisión abierta de Chile, cuyos noticiarios principales se emiten entre las $20 \mathrm{~h} 30$ y las $22 \mathrm{~h} 30$. Algunos se inician media hora más tarde, pero la duración aproximada de todos ellos es de una hora y media. Para el registro, las noticias fueron clasificadas en los aspectos más formales 
por fecha, formato, duración, tipo de presentador y sector temático de la información, mientras que la proyección analítica se estableció en categorías de enfoque (optimista, neutro o pesimista), actantes (personaje y rol actancial) y misión (eje temporal: pasado, presente y futuro).

\section{Análisis y resultados}

Entre los meses de abril y septiembre de 2020 se aplicaron los criterios de selección descritos en los párrafos anteriores para analizar cerca de tres mil noticias difundidas por la televisión chilena, cuyos resultados generales se presentan en los siguientes gráficos.

\section{Gráfico 1}

\section{Protagonistas (héroes) en los noticiarios de la TV chilena (\%)}

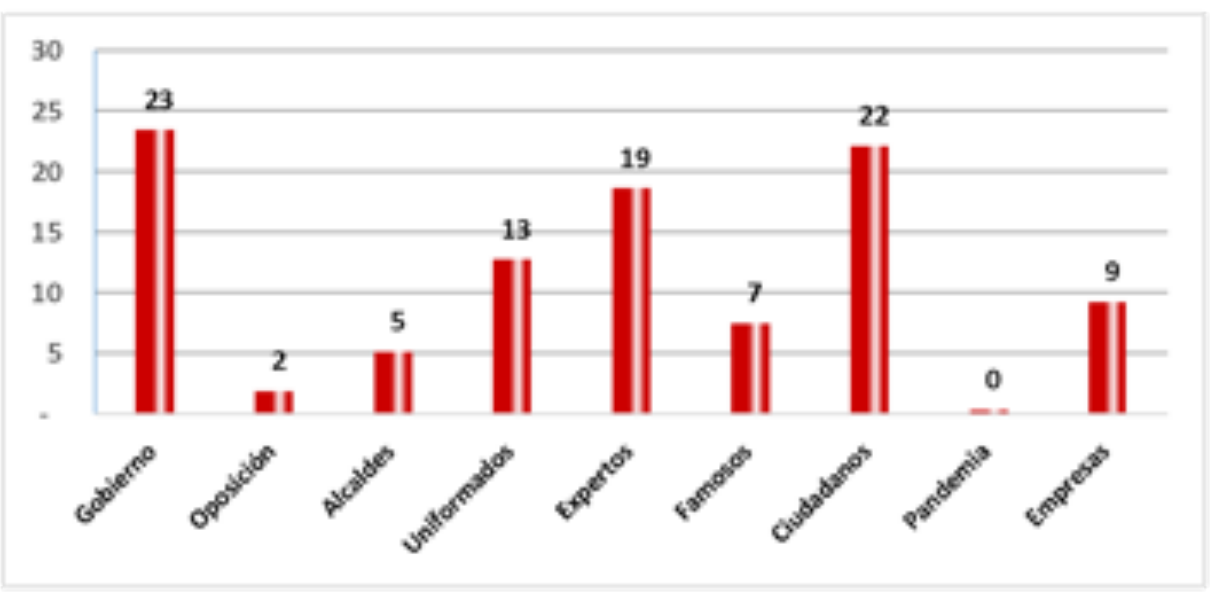

Fuente y elaboración propias

El gráfico de barras da cuenta de que los noticiarios chilenos muestran como protagonistas o héroes, en primer lugar, al Gobierno (23\%), seguido de la ciudadanía (22\%) y los expertos en el tema (19\%). Los actores menos considerados en el rol de héroes son la pandemia (0 \%), los políticos de oposición (2\%) y las autoridades locales, los alcaldes (5\%).

Es interesante notar cómo la exacerbación de los héroes armoniza con un enaltecimiento de la ciudadanía y de los expertos (médicos, científicos, etc.), en los cuales se identifica el "bien". 
Gráfico 2

\section{Antagonistas (villanos) en los noticiarios de la TV chilena (\%)}

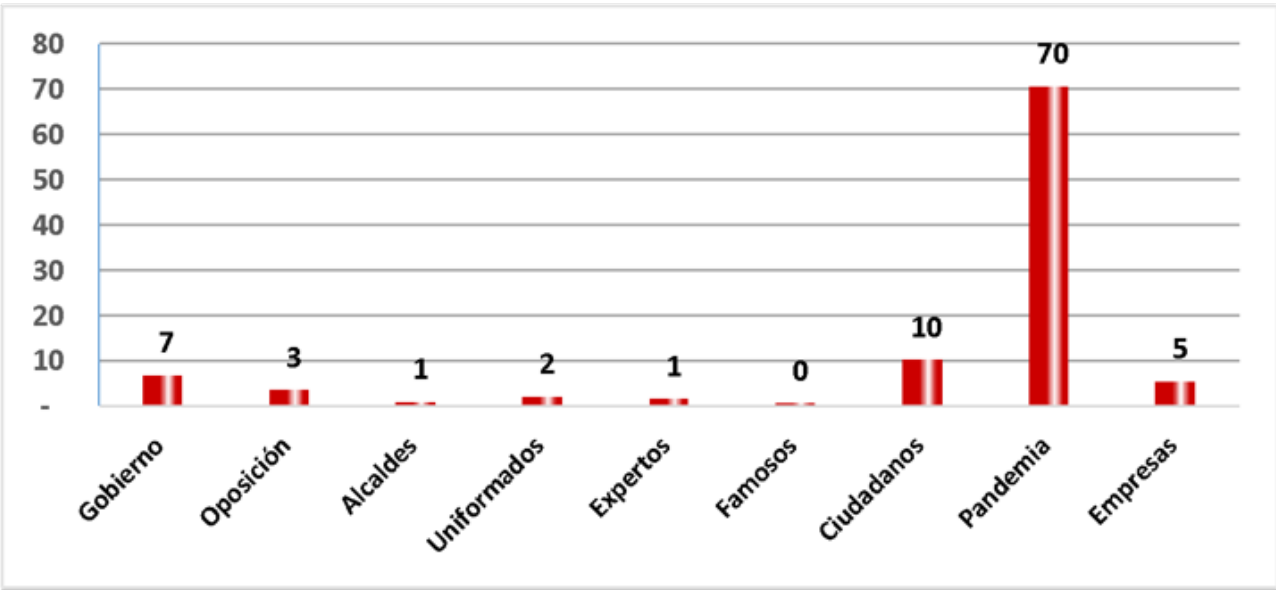

Fuente y elaboración propias

El estudio realizado arrojó que los antagonistas en torno al discurso coyuntural del COVID-19 son encabezados por la pandemia (70 \%), como el principal villano, lo cual es - 170 - lógico por el tipo de relato, en el cual se personificó literalmente al enemigo, en este caso el virus mismo, convertido en "sujeto". Si bien la ciudadanía (10 \%) y el Gobierno (7 \%) figuran como héroes en el gráfico anterior, no hay contradicción explícita, sino que más bien se explica por las pocas voces discrepantes que consigna la televisión chilena abierta o, en algunos casos, por comportamientos particulares de algunas personas.

Gráfico 3

\section{Ayudantes de los héroes en los noticiarios de la TV chilena (\%)}

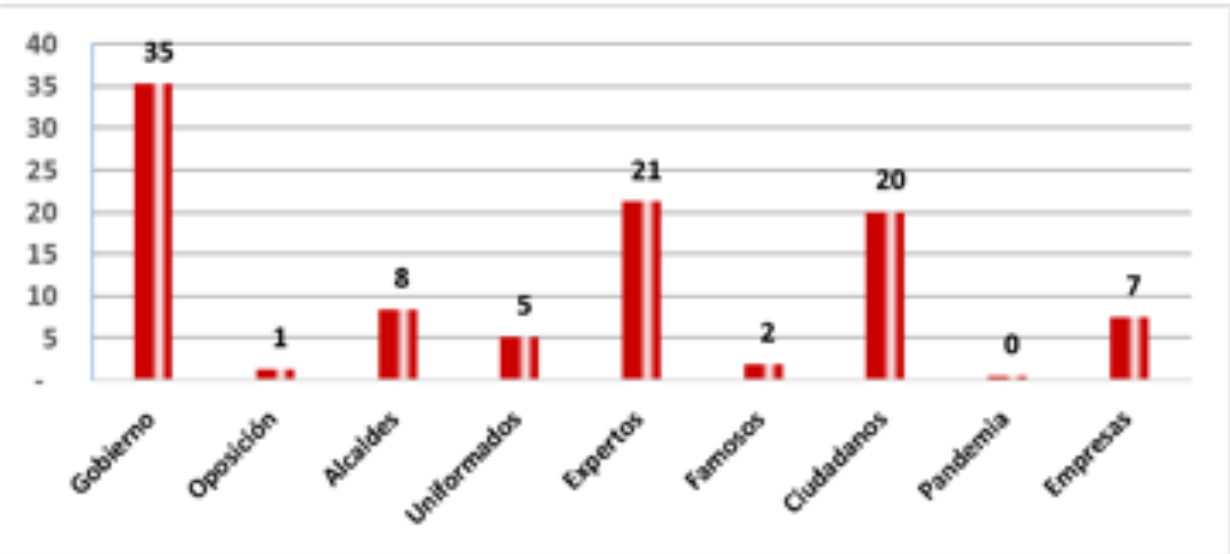

Fuente y elaboración propias 
Según consigna la cobertura mediática de la televisión chilena, los héroes tienen como ayudantes al Gobierno (35\%), los expertos (21 \%) y la ciudadanía (20\%). Los resultados de este gráfico refuerzan la idea de coherencia en la valoración de los medios respecto de los "buenos" del relato, que se vinculan en esta virtud. Es decir, a veces son héroes y otras, colaboradores.

\section{Gráfico 4}

\section{Ayudantes de los antagonistas en los noticiarios de la TV chilena (\%)}

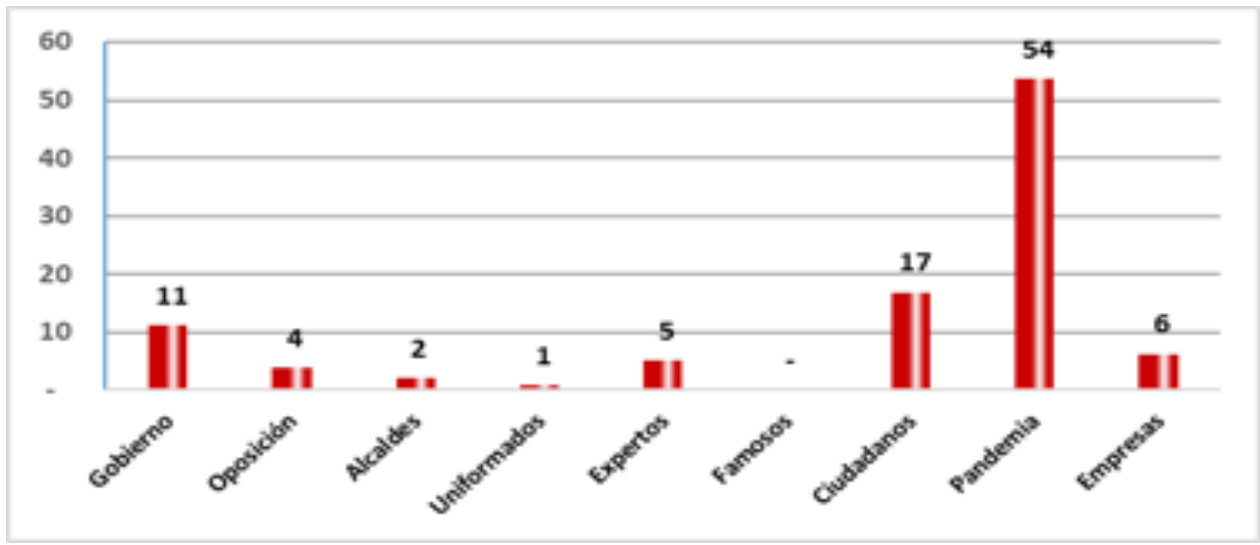

Fuente y elaboración propias

En los resultados de quiénes son los ayudantes de los antagonistas, cuya función es de apoyar a los villanos a cumplir su misión, son la pandemia (54\%), los ciudadanos $(17 \%)$ y el Gobierno (11\%). También se manifiesta en estos resultados una coherencia narrativa en la identificación de roles de "malos" con los mismos actantes, a veces de villanos y otras, de ayudantes.

\section{Gráfico 5}

Misión asignada a los héroes en los noticiarios de la TV chilena (\%)

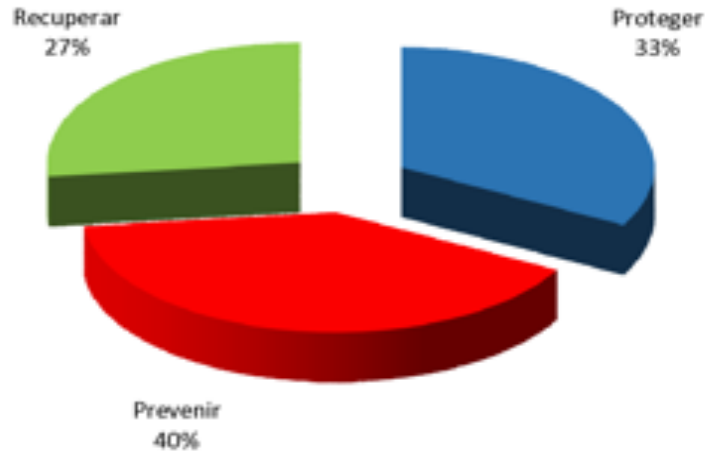

Fuente y elaboración propias 
Para el registro de estos resultados, se consideró la verbalización respecto del eje temporal, ubicando las acciones misionales en el pasado, el presente y el futuro. Si bien hay una suerte de equilibrio en los tiempos, los noticiarios chilenos asignaron a los héroes de esta trama principalmente la misión de prevenir (40\%), seguido de proteger (33\%) y recuperar $(27 \%)$.

\section{Gráfico 6}

\section{Enfoque de los acontecimientos en los noticiarios de la TV chilena (\%)}

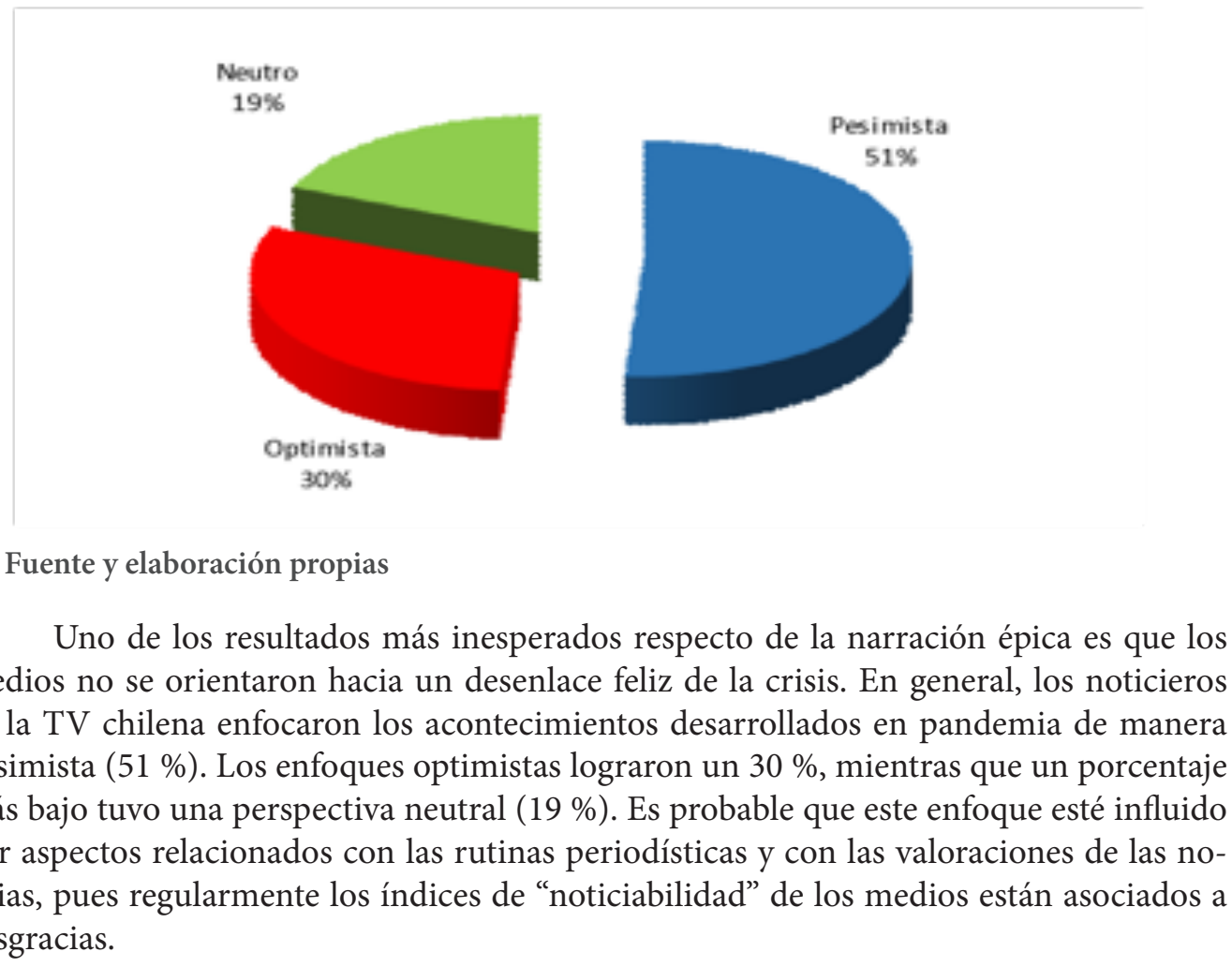

\section{Discusión y conclusiones}

En las redes sociales, el presidente Piñera ha sido objeto de múltiples expresiones de rechazo o burla por sus intervenciones fuera de protocolo, y no solo durante el gobierno actual, sino también durante los cuatro años de su mandato anterior.

Sus alusiones a acontecimientos históricos o referencias culturales, muchas veces erróneas o fuera de lugar, han dado pie a estas manifestaciones jocosas. Lo anterior, sin embargo, no se produce porque haya innovado respecto de la estructura narrativa, que es la misma que despliegan casi todos los actores políticos chilenos, sino por la imprecisión 
de los datos. En particular, el 29 de agosto de 2020, en una visita a Arica, el presidente Piñera expresó lo siguiente:

No ha habido una caída de recursos asignados a la región, sino que se han reasignado porque las prioridades cambian; y cambiaron desgraciadamente por culpa de un virus microscópico e invisible, pero letal y muy destructivo, que se llama coronavirus y al que yo le pido, como presidente de Chile, que nos deje tranquilos, que se vaya del país. (Mur 2020, párr. 2)

En particular, la referencia del presidente Piñera al COVID-19 como sujeto de interlocución no es tan extraña cuando se observa el Gráfico 2, pues los noticiarios de la televisión chilena efectivamente han reproducido un relato épico en el cual el antagonista es un virus, personificado como una figura retórica naturalizada. De hecho, el ministro Mañalich no tuvo la misma repercusión con su discurso pronunciado el 21 de mayo de 2020, en Valparaíso, en el Día de las Glorias Navales.

Estamos luchando contra un enemigo terrible, que se infiltra en nuestras casas, que nos empobrece, que nos hace distanciarnos de nuestros seres queridos, que nos produce incertidumbre, que produce una exigencia para nuestra red de hospitales, para nuestros funcionarios públicos de salud, que también se enferman, también sufren, y que por eso queremos aprovechar el día de hoy para destacar y agradecerles siempre que vemos en ellos a los nuevos héroes. (CL Ministerio de Salud 2020b, párr. 3)

Es que Piñera no es el único protagonista en los relatos de los noticiarios. El rol de héroe se reparte entre las autoridades de Gobierno, los ciudadanos y los expertos (médicos, científicos, etc.). Desde luego, el rol activo del Poder Ejecutivo explica fácilmente su representación épica. Del mismo modo, el prestigio de la ciencia y la dependencia de la población de las instituciones y el personal de la salud justifican que los expertos sean representados como héroes en medio de una pandemia.

Los ciudadanos, en cambio, asumen roles en relación al "orden social”, que es la misión esencial del héroe mítico. Por ejemplo, los medios elogian y destacan a las personas que se atienen a las normas e instrucciones de la autoridad, ya sea respetando las cuarentenas, el lavado de manos o el uso de mascarillas. En cambio, quienes infringen las mismas regulaciones son tratados en el relato como delincuentes.

Si bien las temáticas relativas a políticas contingentes marcan fuertemente la narrativa épica, en términos en que los partidarios del oficialismo y los representantes de la oposición se culpan mutuamente del desastre y se levantan como salvadores de la situación, los medios no enfatizan esta dinámica y más bien sostienen, en cualquier caso, un relato que demoniza - muchas veces aplicando la figura retórica de la personificación - al virus que genera la pandemia. Por su parte, los héroes, que son variados, se instalan con fuerza en una suerte de resistencia, más que en una actividad proactiva.

En efecto, los relatos televisivos levantan como figuras heroicas a los representantes del Gobierno más por su carácter de autoridad que por su posición política. De hecho, 
también los personajes de oposición fueron estimados como héroes, siempre en casos en que el COVID-19 era el "enemigo" común. Por ejemplo, el 7 de octubre de 2020, la presidenta del Colegio Médico, Izkia Siches, acusó en la Cámara de Diputados a "nuestro Ministerio de Salud, liderado por Jaime Mañalich, [que] debilitó aún más la credibilidad institucional, con imprudencia temeraria en el manejo de los datos y con aperturas precoces" (CNN Chile 2020, párr. 2). Por sus intervenciones, regularmente críticas con el Gobierno, la doctora Siches ha adquirido tal prestigio popular que incluso se ha levantado como presidenciable, postulación que ha rechazado, pese a la difusión favorable que le otorgan los medios, incluida la televisión.

Las autoridades uniformadas son presentadas como héroes y principales oponentes a la pandemia, en términos de protección de los "buenos" ciudadanos" (quienes siguen las instrucciones sanitarias o restrictivas) y de "castigadores" de los "malos" (quienes violan los reglamentos o las instrucciones de salud), no obstante que, simultáneamente, figuren como ayudantes o villanos en temas institucionales o en relación a la represión de manifestaciones ciudadanas.

Las misiones asignadas a los héroes de los relatos se distribuyen regularmente en un eje temporal. Respecto del pasado, se pretende que se recupere la "normalidad", mientras que en el presente se manifiesta la necesidad de proteger a la población. Del mismo modo, la proyección en el tiempo se expresa en la función de prevenir la expansión de la pandemia. El 14 de octubre de 2020, la subsecretaria de Salud Pública, Paula Daza, señaló lo siguiente:

Hemos logrado cumplir con medidas de autocuidado en los trabajos, en el transporte público y en la vía pública, pero al interior de nuestras casas, con la gente más cercana y que más queremos, nos relajamos. Eso no puede pasar. Nuestras interacciones sociales intradomiciliarias deben tener cambios que apunten a disminuir el riesgo de contagio. (CL Ministerio de Salud 2020a, párrafo 2)

Quizás los datos más anómalos de esta investigación, los menos esperados, sean los relativos al enfoque de la información, pues la mitad de las veces es pesimista y solo un $30 \%$ se encara con optimismo. Esta suerte de depresión narrativa resulta extraña porque, en general e históricamente, los relatos épicos representan una esperanza, y emergen cuando las crisis parecen superar las competencias humanas. Lo anterior puede reflejar una especie de ánimo social, producto de la serie acontecimientos críticos que ha enfrentado el país, pero también puede ser una modificación de los discursos aplicados regularmente a los relatos épicos. Por ejemplo, el 11 de junio de 2020, el ministro Jaime Mañalich explicó que:

Hemos tenido una baja letalidad del SARS-CoV-2, gracias al soporte que se le ha dado a la red asistencial y a los exámenes PCR que realiza el país, que con más de 781000 pruebas figura entre los primeros puestos de la región. Pero el mes de junio es probablemente el que va a ser más duro, sobre todo por la afectación que tiene en la zona central del país, pues 
Santiago, que es el principal foco de la pandemia y donde la red hospitalaria está al límite, lleva casi un mes bajo confinamiento total, una medida que afecta a siete millones de residentes. (T13 2020, 16:36)

Es probable que en una época de cambios manifiestos, la sociedad chilena o los medios de comunicación estén modificando incluso las estructuras narrativas con las cuales representan la realidad, lo que también explicaría la sorpresiva aparición positiva de ciudadanos comunes y corrientes - la palabra villano deriva de los populares habitantes de las villas-, considerando que los relatos épicos regularmente destacan a seres superiores, vinculados por cierto al poder y que, en este caso al menos, muestran un claro deterioro en su prestigio.

\section{Referencias}

Barría, Cecilia. 2019. "Protestas en Chile: Las consecuencias económicas y de imagen de la cancelación de 2 grandes cumbres internacionales por el estallido social”. BBC News. 31 de octubre. https://bbc.in/3wF1RxQ.

Barthes, Roland. 1994. El mito hoy. Ciudad de México: Siglo XXI.

CL Ministerio de Salud. 2020a. “COVID-19: Subsecretaria Daza participa en lanzamiento de campaña educacional por medidas preventivas en el hogar”. Ministerio de Salud. 14 de octubre. https://bit.ly/3hX30N8.

—. 2020b. "Ministro Mañalich refuerza llamado a la unidad nacional para combatir el covid-19". Ministerio de Salud. 21 de mayo. https://bit.ly/3ut9GoT.

CNN Chile. 2020. "Acusación constitucional contra Mañalich: Siches acusa 'imprudencia temeraria' en manejo de datos”. CNN Chile. 7 de octubre. https://bit.ly/3fTMivs.

Fuentes-García, Alejandra. 2020. "El clamor de las inequidades: Estallido social y salud en Chile”. Revista Chilena de Salud Pública 23 (2): 93-4. doi:10.5354/0719-5281.2020.56343.

García, Agustín. 1996. “Enfermedad, política, progreso”. Archipiélago 25: 15-32. https://bit.ly/3bYljOu.

Gutiérrez, Silvia. 2005. Discurso político y argumentación: Ronald Reagan y la ayuda a los contra. Ciudad de México: Universidad Autónoma Metropolitana.

Hernández Sampieri, Roberto, et al. 2014. Metodología de la investigación. Ciudad de México: McGraw-Hill.

Mur, Robert. 2020. “Piñera le habla al coronavirus y le pide que se vaya del país”. La Vanguardia. 1 de septiembre. https://bit.ly/3vzxuZS.

Neira, Cristian. 2020. “Estamos en guerra’ y 'enemigo poderoso e implacable’: Piñera y la repetición de conceptos estos últimos años”. El Desconcierto. 16 de abril. https://bit.ly/3bZ3qia. 
Páez, Darío, y Juan Pérez. 2020. “Social Representations of COVID-19 (Representaciones sociales del COVID-19)”. International Journal of Social Psychology 35 (3): 600-10. https://doi.org/10.1080/02134748.2020.1783852

Reyes Montes, María Cristina, et al. 2011. "Reflexiones sobre la comunicación política". Revista Espacios Públicos 14 (30): 85-101. https://bit.ly/3x4HavI.

Roa, Yerko. 2019. “Piñera sobre crisis en Chile: 'Estamos en guerra contra un enemigo poderoso”' BioBioChile. 20 de octubre. https://bit.ly/3oVQwXH.

Rojas, Daniela, Constanza Micolich, Mariana Dittborn, y Sofía P. Salas. 2020. "Sobre héroes, enemigos, víctimas y batallas en los tiempos del COVID-19”. Revista Médica de Chile 148 (5): 709-11. https://doi.org/10.4067/s0034-98872020000500709.

Sánchez-Escalonilla, Antonio. 2003. Diccionario de creación cinematográfica. Madrid: Ariel.

T13. 2020. "Coronavirus en Chile: Balance oficial 11 de junio". T13. 11 de junio. https://bit.ly/3gjJvvJ.

Tinto, José. 2013. "El análisis de contenido como herramienta de utilidad para la realización de una investigación descriptiva. Un ejemplo de aplicación práctica utilizado para conocer las investigaciones realizadas sobre la imagen de marca de España y el efecto país de origen". Provincia 29: 135-73. https://bit.ly/3vsRe0V. 